\title{
Cerebral venous thrombosis in Behçet's disease
}
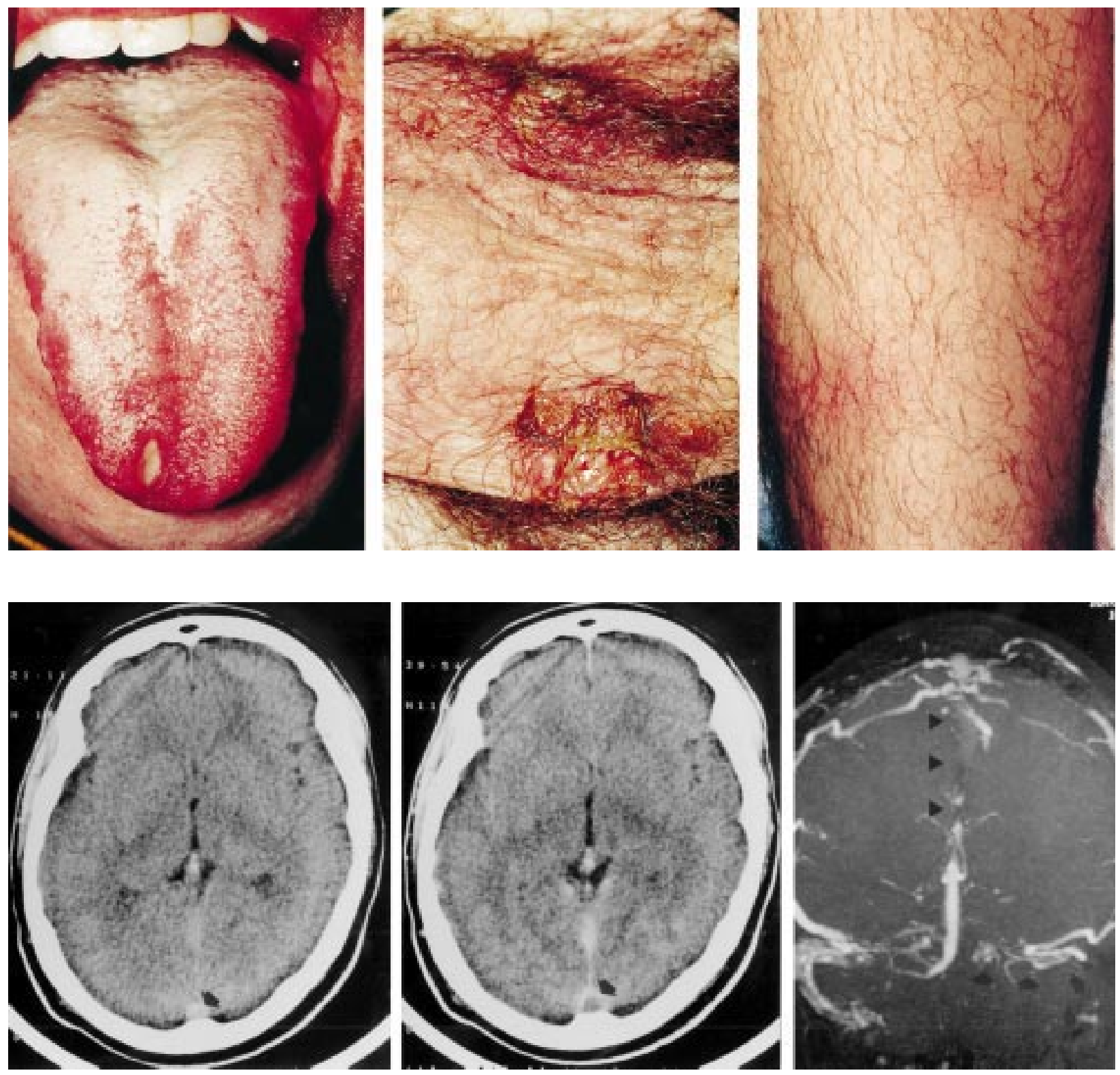

A 22 year old man presented acutely with blurred vision and headache. He had recurrent oral (top left) and genital ulcers (top middle), erythema nodosum (top right), and a positive pathergy test, fulfilling the criteria for Behçet's disease. There was bilateral papilloedema, and a CSF pressure of $45 \mathrm{~cm} \mathrm{H}_{2} \mathrm{O}$. Plain head CT showed a dense triangle (arrow, bottom left) and an empty delta sign after contrast (arrow, bottom middle), suggestive of a superior sagittal sinus thrombosis. Magnetic resonance venography showed a flow void consistent with thrombosis within the superior sagittal and left lateral sinuses (arrowheads and arrow respectively, bottom right).

S FENWICK A GOONETILLEKE C G SANTOSH 